\title{
A COMUNICAÇÃO SOCIAL COMO FERRAMENTA PARA A CONSOLIDAÇÃ̃O DOS PRINCÍPIOS DO COOPERATIVISMO
}

Vilson WAGNER ${ }^{1}$

Luciano ZAMBERLAN ${ }^{2}$

Pedro Luís BUTTENBENDER ${ }^{3}$

Ariosto SPAREMBERGER ${ }^{4}$

Gabriela CAPPELLARI ${ }^{5}$

\author{
${ }^{1}$ Bacharel em Administração , Ceriluz / Unijuí, wagner.alemo@yahoo.com.br \\ ${ }^{2}$ Doutorando, Unijuí, luciano@unijui.edu.br \\ ${ }^{3}$ Doutor, Unijuí, pedrolb@unijui.edu.br \\ ${ }^{4}$ Doutor, Unijuí, ariosto@unijui.edu.br \\ ${ }^{5}$ Mestranda, Unijuí, gabriela.cplr@gmail.com
}

Recebido em: 02/08/2015 - Aprovado em: 03/01/2016 - Disponibilizado em: 30/07/2016

\begin{abstract}
Resumo
Este artigo propõe identificar o papel da comunicação dentro do cooperativismo, especialmente no cumprimento dos sete princípios que norteiam este sistema socioeconômico. Para identificar até que ponto as Assessorias de Comunicação Social conseguem contribuir para a gestão e educação em torno destes princípios, buscou-se realizar uma pesquisa bibliográfica, abordando temas como Comunicação e Cooperativismo. Os resultados apontam que os setores de comunicação social contribuem para a consolidação dos sete princípios, alguns com mais intensidade, outros com menos. Destaca-se o fato dessa contribuição ser bastante ampla, acontecendo no relacionamento direto entre as cooperativas e o associado, por meio de reuniões e assembleias, ou através de veículos de comunicação, especialmente programas de rádios e informativos impressos próprios. A comunicação mostrou-se uma ferramenta indispensável capaz de suprir carências deixadas na área social, que podem surgir no atual contexto socioeconômico globalizado e competitivo, onde a prioridade é a viabilidade econômica das organizações.
\end{abstract}

Palavras-chave: Comunicação. Cooperativismo. Jornalismo. Princípios.

\begin{abstract}
This article proposes to identify the communication paper in the co-operativism, especially in the accomplishment of the seven principles that direct this system. To identify until point the Offices of Social Communication manage to contribute for the administration and education around of these principles, it sought to accomplish a bibliografic research, themes as Communication and Co-operativism. The results point that the sectors of social communication contribute at the consolidation of the seven principles, some with more intensity, other with less. It stands out the fact of this contribution being very wide, happening in the direct relationship between cooperatives and the associate, by means of reunions, or through communication, especially radios programs and informative own printed papers. The communication it showed an able to indispensable, that they can come in the current context globalized and competitive, where the priority is economic viability of the organizations.
\end{abstract}

Keywords: Communication. Cooperativism. Journalism. Principles.

\section{INTRODUÇÃO}

As cooperativas, em sua maioria, surgiram para suprir algum tipo de demanda onde havia carências. Isso aconteceu com as cooperativas de produção, as cooperativas de eletrificação e infraestrutura e até mesmo com aquelas voltadas ao crédito e tantas outras prestadoras de serviços espalhadas no Brasil e no mundo. Contudo, com o passar dos anos e na virada para o século XXI, de pequenas 
organizações voltadas para poucos associados, se transformaram em grandes empresas, abrangendo públicos expressivos e enormes áreas, tornando-se até mesmo referências em negócio nestes locais. As cooperativas são formadas por um grande número de pessoas, chamadas de associados, que têm um objetivo em comum a ser suprido, que não é a obtenção de lucros.

Como empresas que são - apesar do caráter social - se utilizam de uma estratégia muito em voga na atualidade para expandir suas ações e ganhar visibilidade, a comunicação, que pode cumprir diferentes papéis. Contudo, ela precisa ganhar ainda mais espaço no cooperativismo, além do que já ganhou. Ao analisar este tema dentro das organizações, fica claro o seu direcionamento ao marketing, quando este setor tem muito mais a oferecer dentro das cooperativas. É esse o tema que aborda este artigo, intitulado “A comunicação social como ferramenta para a consolidação dos princípios do cooperativismo".

As cooperativas são formadas por associados que colocam à sua frente, representantes eleitos em processos democráticos e que, por isso, têm a obrigação de prestar contas de sua atuação na diretoria da organização. Nos princípios que normatizam o cooperativismo está explícito o direito do associado à transparência e à informação sobre as ações dos seus representantes eleitos. Ajusta-se a estes conceitos a comunicação, que tem como atribuição primeira levar uma mensagem entre o emissor e o receptor, por meio de algum canal de transmissão de informações.

\section{COMUNICAÇÃO - ORIGEM E EVOLUÇÃO}

O mundo está dinâmico e as tecnologias permitem às pessoas estarem interligadas em todo momento, com qualquer parte do planeta. Esse dinamismo nos dá a impressão de que a comunicação acontece com facilidade e efetividade. Quem dá essa impressão são as novas tecnologias de transmissão de informações lideradas, atualmente, não mais pela televisão, mas pelo computador e o fantástico mundo aberto pela internet. Isso, no entanto, é questionável e um dos teóricos que o faz com mais entusiasmo é Marcondes Filho (2002). Apesar de confirmar que as formas modernas de troca de mensagens - lideradas pela internet - ampliam a interatividade e a capacidade de repassar e receber mensagens, ele questiona se isso constitui-se de fato comunicar-se. Habermas (1989) define a comunicação como o novo paradigma sobre a qual o mundo está ancorado, uma vez que as relações sociais atuais são baseadas no fluxo dinâmico de dados e informações.

O processo de comunicação envolve dois sujeitos, o emissor e o receptor, em um 
diálogo com troca de mensagens. Para Marcondes Filho (2002), contudo, a definição de comunicação como o fato empírico de alguém mandar algo a outro por meio de um código não define o que é comunicação. A questão é quanto dessa informação é verdadeira e compreendida pelos sujeitos envolvidos, emissores e receptores? Informação em si não pode ser considerada comunicação. Esta só acontece quando a troca de dados alcança seu objetivo, que é a compreensão das mensagens. Um aspecto que precisa ser levado em conta pelo emissor é a capacidade de decodificação da mensagem pelo destinatário (RICCIARDI, 2000). O entendimento de uma mensagem vai depender do modo como ela está sendo enviada - com clareza, objetividade e com o canal apropriado - e ainda do fato do receptor ter a mínima compreensão do tema e da linguagem utilizada.

\subsection{A Comunicação Institucional}

Normalmente quando se fala em comunicação com clientes dentro das empresas pensa-se logo em Marketing Institucional. Este setor tem em seu leque de funções a coordenação das campanhas de marketing, porém, sua função é muito maior e definida como Comunicação Institucional. Para Cides (2009) Marketing Institucional é o trabalho realizado pelas empresas para melhorar a sua imagem junto a um determinado público.

Para Rosa (2004) a correta gestão do marketing "determinará procedimentos eficientes em relação ao mix de produtos, a políticas de relacionamento com o cliente, ao posicionamento da marca e ao atendimento pós-venda”. Portanto, o marketing é um trabalho diretamente atrelado ao setor administrativo da empresa, onde a Assessoria de Comunicação Social entrará como um suporte técnico. A Comunicação Institucional, também chamada de Comunicação Empresarial, na essência, busca projetar uma imagem favorável junto aos seus públicos, contudo, não está tão embasada na venda e na semiologia - símbolos e marcas - mas sim em levar as informações sobre o trabalho que a organização presta e suas consequências no meio social onde está inserida.

\subsection{Assessoria de Comunicação Social}

A complexidade do conceito de comunicação tornou necessária a existência de pessoas capacitadas a gerenciarem as informações. Destarte, os meios de comunicação se profissionalizaram e passaram a contar com jornalistas e publicitários qualificados. Atualmente, administradores começam a ver a comunicação como uma ferramenta benéfica para a imagem da empresa e querem usá-la, não de forma paliativa, mas preventiva e, por 
isso começam a inserir dentro das organizações as Assessorias de Comunicação Social (ACS).

Rego (1984) destaca que o uso das funções da comunicação é um dos fenômenos mais característicos da sociedade moderna, sendo apontado inclusive como fundamental para a sobrevivência e desenvolvimento das organizações, portanto, deve ser vista com bons olhos pelos administradores. Para Kopplin (1996) as empresas usam das Assessorias de Comunicação Social para aprimorar o fluxo de informações geradas no dia a dia da organização, tanto com os públicos internos quanto externos. A ACS presta um serviço especializado, coordenando as atividades de comunicação de um assessorado com seus públicos e estabelecendo políticas e estratégias que englobam iniciativas nas áreas de Jornalismo (assessoria de imprensa), Relações Públicas e Publicidade e Propaganda (KOPPLIN, 1996, p.17).

A Assessoria de Comunicação Social está definida no organograma apresentado na Figura 1. Ao jornalista cabe administrar as informações jornalísticas, a editoração dos canais próprios de comunicação - boletins, revistas e informativos - e a relação da empresa com os veículos de comunicação externos. Conforme Kopplin (1996) este profissional deve intermediar as relações entre a organização assessorada e os meios de comunicação, contatando editores e diretores ou fazendo contato via mailings; editando periódicos destinados aos públicos interno e externo; elaborando produtos jornalísticos diversos, além de organizar arquivos com as informações veiculadas pela imprensa, seja aquelas enviadas pela assessoria, ou aquelas não oficiais, oriundas de entrevistas públicas dos diretores.

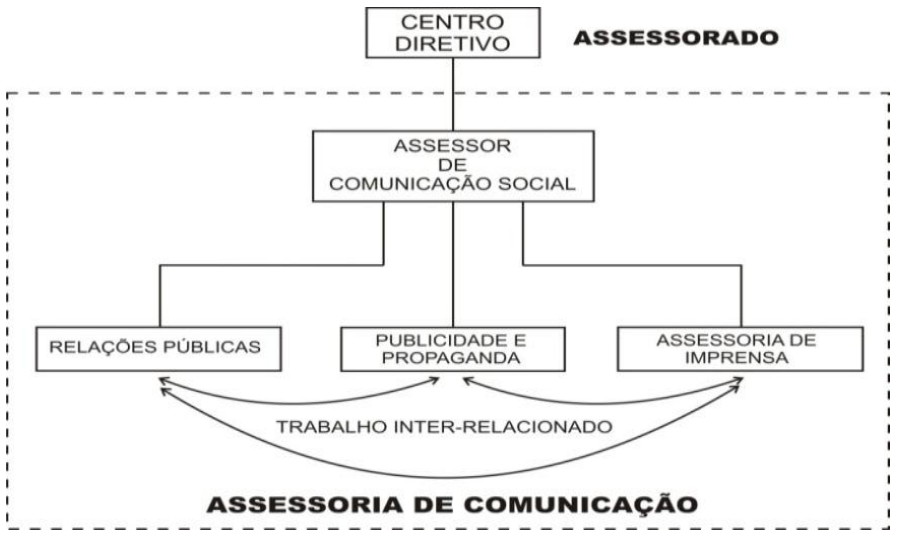

Fonte: Kopplin (1996)

Figura 1: Organograma Institucional com a Posição da ACS

\subsection{Assessoria de Imprensa ou Jornalismo}

\section{Empresarial}

Apesar do crescimento das Assessorias de Comunicação Social dentro de organizações, o destaque ainda é para a publicidade e os serviços de relações públicas. São poucas as organizações que incluem em seu quadro funcional um jornalista, responsável por gerir as informações. No entanto, a hegemonia dos veículos de comunicação - jornais, rádios e TVs - vem 
exigindo dos diretores uma nova postura frente a isso e estes, acabam apostando em uma Assessoria de Imprensa (AI) para organizar seu relacionamento com os veículos de comunicação de massa. Segundo Rego (1984) um dos fenômenos da sociedade atual é o crescimento das funções de comunicação para a sobrevivência e desenvolvimento das organizações. Um dos segmentos mais significativos do que se pode chamar de comunicação empresarial certamente é o do Jornalismo Empresarial que, junto com as Relações Públicas e a Propaganda, formou o tripé clássico que organiza os fluxos irradiadores de opinião em torno das organizações.

Esta resistência à Assessoria de Imprensa não tem origem apenas nas diretorias das organizações, mas por muito tempo - e ainda hoje - o Jornalismo Empresarial foi considerado por profissionais da área uma função menos importante comparado à grande imprensa e é por isso chamada de pequena imprensa. Porém, para Rego (1984), este gênero precisa ser analisado como uma proposta especializada da atividade jornalística, que visa aperfeiçoar o conceito imagético da empresa que assessora e sua identidade institucional.

Conforme Pena (2007), a notícia é a matéria prima do jornalismo e é este profissional que precisa identificar o que é o que não é relevante noticiar, publicando apenas o que é de interesse da sociedade. Segundo o autor, levar a informação certa é mais que "a chave para compreender o seu significado, é contribuir para o aperfeiçoamento democrático da sociedade". Esta ideia refere-se principalmente ao jornalismo praticado nos veículos de comunicação de massa, mas não pode, de forma alguma, se distanciar do Jornalismo Empresarial. Kopplin (1996) completa este pensamento e traz a teoria da contribuição do jornalista na construção da realidade social para o nível da Assessoria de Imprensa, afirmando que este profissional influencia nas decisões e ações das pessoas. O trabalho do assessor de imprensa está relacionado com a formação da opinião pública, na medida em que pretende atingir um determinado número de pessoas com uma mensagem.

A teoria do espelho não seria possível, inteiramente, em nenhum dos casos, afinal, por mais objetivo que o jornalista tente ser, apenas relatando os fatos, ele é um sujeito com emoções e formas de pensar próprias. Por isso Rossi (1981) define a objetividade (imparcialidade) do jornalista como um mito, uma vez que este, quando escreve, repassa parte do que sente, subjetivamente. Se tratando de uma informação institucional, essa emoção pode ficar ainda mais latente, afinal, o jornalista vive a realidade da empresa e precisa tentar repassar da forma mais fidedigna possível os fatos vivenciados na 
organização. Como o jornalista está diretamente ligado à direção, normalmente pensa como esta e, portanto, vai buscar fazer prevalecer os ideais institucionais. Isso claro, desde que não ocorra um choque com os princípios éticos que regem sua vida e sua profissão.

\section{Cooperativismo e seus Princípios}

Para Ocergs/Sescoop/RS (2001) o cooperativismo é um movimento de âmbito internacional, que tem o objetivo de libertar o homem do individualismo, através dos atos de cooperação entre os indivíduos. Ajuda a constituir uma sociedade mais justa e livre, onde, através da organização social e econômica das comunidades em bases democráticas, consegue atender às necessidades das pessoas, remunerando 0 trabalho de cada um dos cooperados. As cooperativas diferenciam-se das empresas tradicionais por buscarem satisfazer às necessidades de seus associados, sendo que, “as pessoas que optam pelo cooperativismo o fazem pela solidariedade, a transparência, a democracia, a equidade e a promoção da justiça social". Segundo ele, esta organização amplia a capacidade das pessoas a enfrentarem os desafios da vida. A cooperação contribui para o desenvolvimento das competências individuais e organizacionais, sustentando a perenidade das firmas e a perpetuação do trabalho e dos negócios. (BÜTTENBENDER, 2011).

A origem do cooperativismo comprova seu espírito social baseado na organização do trabalho. Oficialmente surgiu no ano de 1844, pelos chamados Pioneiros de Rochdale, em Manchester, na Inglaterra, quando foi formada a primeira cooperativa dentro dos atuais princípios, que se consolidaram ao longo dos anos de sua existência. O período era marcado pela Revolução Industrial e os problemas sociais se agravavam, especialmente em razão do desemprego causado a partir do surgimento da máquina a vapor. Estas tecnologias, modernas para a época, juntaram-se às novas formas de organização de trabalho, tornando obsoleta boa parte da mão de obra humana. Muitos dos impactos ocorridos na época são ainda hoje percebidos, como o crescimento desordenado das cidades, impactos ambientais e o aumento da pobreza e da marginalização. Foi neste contexto que um grupo de tecelões da cidade inglesa de Rochdale organizou a primeira cooperativa formal, buscando sanar as necessidades que lhes eram impostas pelo capitalismo, em franca expansão. Nascia então a Sociedade dos Probos de Rochdale, que montou um pequeno armazém e que, em 1860, já contava com 3.450 associados.As normas de organização e de funcionamento defendidas pelos tecelões que criaram essa cooperativa a partir das ideias dos precursores 
passaram a constituir não somente o modelo cooperativista adotado em todo o mundo, como também a própria base da filosofia do cooperativismo (OCERGS, SESCOOP, 2001, p.17).

No Brasil, segundo a Organização das Cooperativas Brasileiras (OCB) o sistema cooperativista foi registrado pela primeira vez, em 1889, através de uma cooperativa de consumo em Minas Gerais, denominada de Sociedade Cooperativa Econômica dos Funcionários Públicos de Ouro Preto, expandindo-se posteriormente para os demais estados, com destaque para o cooperativismo de crédito e de produção, no Rio Grande do Sul, a partir do início do século XX. Neste estado este sistema foi bastante estimulado pelos imigrantes europeus, especialmente alemães e italianos, que traziam a cultura cooperativista consigo, influenciados pelas ideias difundidas na Europa a partir da Revolução Industrial, fator que foi, aliás, determinante para sua vinda ao Brasil. Em 02 de dezembro de 1969 foi criada a Organização das Cooperativas Brasileiras, entidade que defende os interesses do sistema no país, apoiada pelas federações e confederações das diversas cooperativas brasileiras, cada uma em seu ramo. Em 1988, surge o Serviço Nacional de Aprendizagem do Cooperativismo (Sescoop) com a missão de ser um disseminador do conceito do cooperativismo como prática de trabalho e produção, qualificando associados, funcionários e a sociedade como um todo.

Ricciardi (2000) defende que o cooperativismo é uma filosofia de vida que vai muito além da organização da produção ou do trabalho. Paré (2009) reforça que o cooperativismo supera a união para a defesa de interesses ou causas pessoais, sendo que as pessoas o adotam com o objetivo de empreender, estando baseado em uma nova forma de agir e pensar. Segundo ele, este sistema representa uma alternativa mais justa e humana para o desenvolvimento, valorizando pessoas, seus talentos, distribuindo oportunidades com igualdade e justiça social.

O cooperativismo tem desde seu início conceitos que o regem e que são chamados de princípios cooperativistas. Todas as organizações que se formam julgando-se cooperativas devem seguir estes valores, que têm em seu núcleo central os associados, que são os fundadores da organização, ao mesmo tempo donos e clientes. Estes princípios, segundo Ocergs/Sescoop (2001), são sete:

$1^{0}$ - Adesão voluntária e livre: todas as pessoas estão aptas a utilizarem os serviços e assumirem às responsabilidades como membros de organizações cooperativas, não podendo haver discriminações de nenhum tipo.

\section{$2^{\circ}$ - Gestão democrática pelos}

membros: assim como a adesão é livre, todos 
os associados têm o direito de participar ativamente da administração das cooperativas, ajudando aos membros da diretoria a tomar as decisões, ou até mesmo, serem eleitos para cargos de diretoria, como representantes dos demais.

\section{$3^{\circ}$ - Participação econômica dos}

membros: os associados, quando aderem a uma cooperativa, contribuem igualmente para o capital de suas organizações e esse capital passa a ser propriedade comum da cooperativa.

$4^{\text {o }}$ - Autonomia e independência: as cooperativas são organizações autônomas e independentes e assim devem manter-se, controladas apenas pelos seus membros fundadores.

\section{$5^{\circ} \quad$ Educação, formação e}

informação: todos os cooperados têm igual direito à formação, sejam eles membros da diretoria, trabalhadores ou associados, focando o conhecimento geral e o desenvolvimento das mesmas.

$6^{0}$ - Intercooperação: prevê a união entre cooperativas como uma forma de fortalecer o setor e os conceitos do cooperativismo.

$7^{\circ} \quad-$ Compromisso com a comunidade: as cooperativas devem contribuir para o desenvolvimento econômico, cultural, social e ambiental de suas comunidades, gerando vagas de trabalho, prestando serviços e ofertando produtos de qualidade, pensando sempre na sustentabilidade, ou seja, gerando desenvolvimento sem prejuízos ao meio comunitário.

Estes são os princípios que regem o cooperativismo desde sua origem, até mesmo antes dele ter um conceito formalizado e disseminado aos quatro ventos. Mesmo aquelas pessoas que ainda não estão diretamente engajados ao sistema conhecem de forma superficial estas ideologias. Para Irion (1997), citado por Pacheco (2010) a cooperação fundada em princípios doutrinários ajudam a modificar o meio econômico e social, aos poucos, primando por valores como democracia, liberdade, equidade, solidariedade e justiça social. A falência de sistemas como o socialismo e o comunismo e até mesmo as críticas sobre o capitalismo fazem crescer a atenção para o cooperativismo, apontado por muitos como a nova alternativa econômico/social para este terceiro milênio, uma vez que ele busca o equilíbrio entre o capital e os interesses da comunidade e não apenas o lucro indiscriminado, como as empresas privadas.

$\mathrm{O}$ crescimento das desigualdades e das necessidades das pessoas foi um terreno bastante fértil para o cooperativismo. Para Ricciardi (2000), após a queda do muro de Berlim, "as cooperativas deixaram de ser a $3^{\mathrm{a}}$ via entre o capitalismo e o socialismo e remanesceram como única proposta 
alternativa". Assim sendo começaram a surgir uma gama de novas cooperativas que passaram atender áreas até então não atendidas por este sistema.

Segundo Büttenbender (2011), as cooperativas estão repensando suas estratégias e incorporado novas competências para atuar no ambiente de competitividade crescente, voltando-se para as capacidades internas e externas das organizações.

\section{METODOLOGIA DA PESQUISA}

Este artigo aduz dois estudos de caso, sendo o primeiro voltado para as organizações que integram a Federação das Cooperativas de Eletrificação e Infraestrutura do Rio Grande do Sul (Fecoergs), verificando de forma ampla as estratégias de comunicação adotadas por suas filiadas e seus resultados, e o segundo para a Cooperativa Regional de Energia e Desenvolvimento Ijuí Ltda. Ceriluz Distribuição - e a Cooperativa de Geração de Energia e Desenvolvimento Social Ltda. - Ceriluz Geração. O objetivo do primeiro estudo de caso foi analisar principalmente quais os canais de comunicação utilizados pelas cooperativas, seus públicos principais e a expectativa quanto ao cumprimento dos princípios cooperativistas. Para isso, foi fundamental analisar de forma prática essa vivência, utilizando-se de um questionário dirigido especificamente para o grupo de 15 cooperativas de distribuição de energia, filiadas à federação. Oito questões foram encaminhadas aos respectivos setores de comunicação, algumas de múltipla escolha e outras dissertativas, abordando os principais canais de comunicação adotados por estas, os tipos de informações divulgadas e quais os princípios alcançados por meio destas atividades comunicativas. Das 15 cooperativas contatadas, via telefone e email, oito encaminharam as respostas, a partir das quais foi feita a análise dos processos de comunicação adotados. Para preservar à imagem destas organizações que responderam ao questionário, ao invés dos seus nomes jurídicos, elas serão numeradas de 1 a 8 , sendo chamadas assim de Cooperativa 1, Cooperativa 2 e assim sucessivamente.

Considerando os resultados obtidos neste primeiro estudo e visando a melhor compreensão de como cada um dos sete princípios podem ser auxiliados pela Assessoria de Comunicação Social, realizouse um novo estudo de caso, desta vez, mais específico, focando o trabalho do setor dentro das cooperativas Regional de Energia e Desenvolvimento Ijuí Ltda. - Ceriluz Distribuição - e de Geração de Energia e Desenvolvimento Social Ltda. - Ceriluz Geração. Em termos gerais, apesar de responderem como duas pessoas jurídicas, as equipes destas cooperativas atuam de forma unificada, no mesmo prédio, apenas com 
negócios diferentes. Sendo assim, a Ceriluz, citando-a de forma genérica, está sediada no município de Ijuí e trabalha com geração e distribuição de energia elétrica, para um público associado de 14,2 mil associados, atingindo 23 municípios da região noroeste do Rio Grande do Sul, sendo 13 na totalidade do meio rural. Seu público compreende principalmente consumidores rurais, mas engloba ainda indústrias, comércio e órgãos públicos. Fundada em 20 de agosto de 1966, possui uma história e uma marca consolidada, completando 45 anos em 2011. O estudo está baseado na análise de seus veículos de comunicação, especialmente do programa de rádio Informativo Ceriluz - durante o período de janeiro a setembro de 2011 - e na maneira como este contribui para o cumprimento dos sete princípios do cooperativismo.

A abordagem adotada neste artigo configura uma pesquisa exploratória que, conforme Malhotra (2001), tem como principal objetivo fornecer informações que possam embasar uma "situação-problema" a qual o pesquisador se propõe a responder. Sampieri (1991) complementa, afirmando que este tipo de estudo normalmente é utilizado quando existem poucas informações bibliográficas sobre o tema em questão.

O tema escolhido é importante pelo fato da comunicação vir se tornando um dos grandes paradigmas da atualidade, o que não é diferente no meio empresarial. Os administradores começam a perceber que a integração com seu público é fundamental no processo comercial e investem em campanhas para melhorar a imagem de sua empresa, assim como buscam relacionar-se bem com os meios de comunicação, para que a opinião pública fale bem de sua marca. Os diretores das cooperativas também já se deram conta disso, no entanto, ainda em menor proporção.

\section{ANÁLISE DOS DADOS E RESULTADOS}

\subsection{A Comunicação Social como} ferramenta para a consolidação dos princípios do cooperativismo

No caso de uma cooperativa, o trabalho da Assessoria de Comunicação Social é ainda mais amplo e fundamental. Nas cooperativas seu papel central é garantir a informação ao associado que, como já verificamos, é o verdadeiro dono da organização. Esse direito à informação, aliás, está explícito no $5^{\circ}$ princípio, que define como direito inquestionável do associado a educação, a formação e a informação. É a Comunicação Institucional que vai abrir espaço para a concretização deste princípio. A informação é um elemento vital nesse sistema de trabalho e que, sem um processo de comunicação bem gerido, não será possível sua concreta efetivação. Trata-se de um processo diferenciado das organizações privadas onde as informações podem - ou até 
devem - ficar centralizadas nas mãos dos seus proprietários e alguns poucos gerentes, de modo que eles possam tomar suas decisões para atingir seus objetivos, não permitindo que elas vazem e favoreçam seus concorrentes. Não dá para esquecer que o objetivo destas organizações particulares é unicamente o lucro, o crescimento dos recursos materiais de seus proprietários e de forma alguma o desenvolvimento coletivo. É bem verdade que $o$ industrial ou $o$ comerciante privado pode visar atender às necessidades de seus clientes, mas isso não ocorre pensando em aumentar o bem estar deste e de suas famílias, mas sim, com a intenção de aumentar as vendas. Diferente das cooperativas que são organizações que unem pessoas com o objetivo de sanar necessidades coletivas e não individuais, com a intenção de disponibilizar serviços ou produtos de qualidade, a preços justos a todos, pensando em sobras que devem ser reinvestidas em ações sociais que beneficiem à comunidade. Sendo ela uma organização composta de muitos donos, seus associados, todos querem e têm o direito de saber o que está acontecendo dentro dela. Como se faz isso? Apenas com um sistema eficiente de comunicação, que vai muito além das Assembleias Gerais Ordinárias. A informação é uma ferramenta indispensável para garantir a transparência das ações da diretoria eleita e funciona como um processo de prestação de contas.

Fica claro o papel da Assessoria de Comunicação Social no cumprimento do $5^{\circ}$ princípio cooperativista, que deixa a palavra informação explícita. Contudo, a intenção deste artigo é verificar se o setor tem um papel mais amplo na consolidação dos demais princípios que o cooperativismo segue. É preciso traçar as características da comunicação dentro das organizações cooperativas, focando no cumprimento dos princípios cooperativistas, pensando não só em vender a marca, produtos ou serviços, mas em satisfazer às necessidades do quadro social, que quer a transparência das ações de seus representantes. Como elemento fundamental dentro deste quesito está o Jornalismo Empresarial, que apresenta papel crucial dentro das cooperativas, uma vez que a propaganda e o marketing não irão saciar às necessidades dos associados e os profissionais de relações públicas o farão parcialmente.

\subsection{Estudo de caso 1: as Cooperativas da} Fecoergs

Questionados na primeira questão, sobre quais os canais de comunicação que utilizam para se relacionar com seu público, todas as possibilidades de respostas oferecidas - assembleias; reuniões com associados; atendimento nos escritórios; inserção de publicidade em veículos terceirizados; 
inserção de notícias em veículos terceirizados; veículos de comunicação próprios; folderes; flyers e redes sociais - foram marcadas por uma ou outra cooperativa, porém, nenhuma afirmou utilizar-se de todos estes meios de entrar em contato com seu associado. Isso demonstra que, por um lado, as cooperativas estão empenhadas em gerenciar sua comunicação com seu público, contudo, ainda existem distâncias expressivas entre as ações de umas e de outras.

A maioria das cooperativas considera os eventos e encontros diretos com os associados canais importantes de comunicação, sendo que sete $(87,5 \%)$ marcaram as assembleias, reuniões com associados e o atendimento nos escritórios como momentos fundamentais de comunicação. Apenas a Cooperativa 1 não apontou às assembleias e os atendimentos nos escritórios como canais de comunicação entre organização e seu público. Quanto aos veículos de comunicação, propriamente ditos, as informações foram mais variadas: $50 \%$ afirmam utilizar de inserções de publicidades em veículos de comunicação terceirizados; $75 \%$ inserem notícias da cooperativa em veículos de comunicação terceirizados; $62,5 \%$ possuem veículos próprios de comunicação e $50 \%$ utilizam folderes. Apenas a Cooperativa 3 afirma utilizar-se de flyers e a Cooperativa 2 das redes sociais para se comunicar com seu público.
Percebe-se que falar em comunicação não é falar apenas em processos de troca de mensagens via veículos de comunicação contemporâneos - impressos, rádios, televisão e internet - mas, do processo como um todo, que parte da premissa da troca de informações entre os cooperados e seus representantes, o que pode ser feito nas assembleias, eventos de educação cooperativista, call centers e por meio de uma série de outros canais. É o que Marcondes Filho (2002) define como as três formas de comunicação: a comunicação pessoal, a comunicação irradiante e a comunicação espectral.

A comunicação pessoal define-se como aquela onde não há interferência de meios de comunicação tecnológicos e apenas a presença física do emissor e do receptor na troca de mensagens, podendo ser apenas duas pessoas ou um grande grupo social. Refere-se a um diálogo aberto, onde todos podem interagir de forma igualitária, opinando, sugerindo, concordando ou discordando. É verdade que alguns atos comunicativos contemporâneos podem ser enquadrados dentro da comunicação pessoal, mesmo com intermediação de equipamentos. É o caso, por exemplo, do diálogo via telefone, onde apesar da distância, ocorre uma conversa direta entre os envolvidos no processo. A comunicação irradiante ocorre quando há um pólo emissor, explícito ou anônimo, que emite informações para um grande público de anônimos, 
posicionadas em massa sendo a mensagem não direcionada a uma pessoa específica. Ocorre em reuniões públicas, palestras e audiências com o propósito de discutir temas de relevância social. A comunicação espectral, por sua vez, é aquele que se utiliza de meios impressos ou eletrônicos de grande alcance, que são atualmente os meios de comunicação: jornal, rádio, televisão e a internet. Uma vez emitida à informação não há como se controlar quem a irá receber, podendo ser qualquer um.

É possível se identificar as três formas de comunicação no sistema cooperativista. $\mathrm{O}$ primeiro e mais básico á a comunicação pessoal, que ocorre principalmente na troca direta de informações entre o colaborador e o associado, entre a diretoria e o associado, entre a diretoria e o colaborador ou entre colaboradores. Ela é chamada por Marcondes Filho (2002) de "o face-a-face", que segundo ele, não é muito efetiva por ser um procedimento ritualizado e um tanto teatral, quando as pessoas representam, simulando seus gestos e falas, onde pouca informação é efetivamente passada, uma vez que "as estratégias de conservação de certos padrões de convivialidade conquistados são rigorosamente mantidos". O segundo modelo de comunicação que podemos identificar nas cooperativas a partir do estudo realizado é o irradiante, ou seja, aquele baseado na troca de informações da organização para um grande público em eventos de cunho social, neste caso específico, assembleias e eventos voltados à formação, educação e informação. A terceira forma de comunicar começa a ser percebida nas organizações cooperativas, em algumas com mais e outras com menos intensidade. Trata-se de comunicação espectral que visa atingir um público maior e utiliza-se de códigos e meios de comunicação específicos para isso. Esta se torna mais efetiva uma vez que tem como propósito básico levar unicamente a informação e perde os vínculos emocionais, especialmente quando houver um profissional qualificado que se utilize de meios adequados para isso.

Este ponto também foi pesquisado entre as cooperativas da Fecoergs. Na questão número dois buscou-se ver quais os veículos de comunicação mais utilizados pelas cooperativas para levar as informações ao seu público, especialmente aos associados. Sem dúvida nenhuma despontou o rádio, apontado por sete cooperativas $(82,5 \%)$ como o principal meio utilizado, o que é justificado principalmente pelas características de seus públicos, principalmente rural. O responsável pelo setor de comunicação da Cooperativa 1, por exemplo, justifica essa importância com o fato de $90 \%$ dos associados serem agricultores, sendo o rádio o meio mais rápido para levar a informação, sem que as pessoas precisem parar suas atividades diárias para saber as notícias da cooperativa, podendo, 
inclusive, levar o aparelho para qualquer lugar.

Seguindo a ordem de importância, os veículos impressos foram colocados na segunda colocação. Apenas a Cooperativa 3 destacou jornais, revistas e boletins na terceira colocação, atrás da televisão, inclusive. A internet e a televisão, por sua vez, alcançaram a terceira e quarta posições, respectivamente, sendo a internet (websites) utilizada como complemento aos demais veículos, e a televisão, em último, mais voltada ao marketing publicitário e a apresentação da marca das organizações.

Divulgando informações institucionais por meio de veículos externos terceirizados a organização adere à chamada comunicação de massa que, segundo Rego (1984) é pública, rápida e efêmera, porque as mensagens não são transmitidas para ninguém especificamente, visam grandes audiências e são de absorção imediata. Fica claro que essa comunicação está embasada principalmente no jornalismo e, neste aspecto específico, identifica-se principalmente o chamado Jornalismo Informativo, um dos gêneros destacados pelo teórico, que se baseia exclusivamente no release, ou seja, na notícia, no relato puro dos acontecimentos, sem interpretações ou opiniões.

O objetivo principal das cooperativas, no entanto, não é atingir a um público tão amplo, mas sim, àqueles que estão diretamente envolvidos com elas, os associados, apontados na pesquisa como o principal público para $100 \%$ das cooperativas que responderam o questionário. Em seguida encontram-se os colaboradores, incluídos no público alvo por $75 \%$ das cooperativas. Outros $62,5 \%$ almejam também a sociedade em geral quando veiculam suas informações nos veículos, terceirizados ou próprios. A Cooperativa 3 destaca ainda que é fundamental as informações chegarem às lideranças políticas e à opinião pública.

Sendo assim ganham importância os veículos próprios das organizações, que se desligam do conceito de comunicação de massa no momento em que são direcionados a um público específico. Ao mesmo tempo munem-se de novos elementos narrativos que tornam essa comunicação mais aprimorada, a ponto de podermos identificar dois outros gêneros apresentados por Rego (1984): o Jornalismo Interpretativo, que busca uma maior profundidade nos fatos, analisa detalhes e aponta sua relevância, onde se incluem reportagens, entrevistas e matérias de pesquisa; e o Jornalismo Opinativo, que expressa julgamentos a partir dos fatos, chega a conclusões e busca persuadir ou influenciar condutas.

A diversidade de informações mostrase saliente nas cooperativas pesquisadas, abordando temas bastante variados. Todas, claro, veiculam principalmente notícias sobre 
energia elétrica e cooperativismo (87,5\%), temas não apontados como primordiais somente pela Cooperativa 4, que aponta o uso dos veículos de comunicação apenas para divulgação de ações de utilidade pública. Destacam-se ainda temas como agricultura entre $50 \%$ das organizações, utilidades públicas (50\%), administração (50\%), saúde (50\%), educação (50\%), social (50\%), tendências (25\%) e negócios (12,5\%). Nenhuma das cooperativas afirmou divulgar notícias esportivas, piadas, palavras cruzadas e horóscopo. A Cooperativa 2 ressaltou que divulga ainda entrevistas com associados e lideranças, sempre voltadas ao trabalho da cooperativa e ao desenvolvimento regional. A Cooperativa 7 lembrou que são veiculadas também orientações e dicas para uso da energia elétrica com segurança e economia.

Embora os veículos de comunicação de massa também apresentem essa diversidade de gêneros jornalísticos, e até mais, o jornalismo realizado nas organizações tem características que permitem enquadrá-lo na categoria de Jornalismo Empresarial. O jornalismo se destaca no relacionamento das cooperativas com os veículos de comunicação, sejam eles terceirizados ou próprios, como nos mostra a pesquisa realizada, afinal, $75 \%$ das cooperativas colocam a transmissão da informação como o principal objetivo a se alcançar através dos veículos de comunicação. Apenas duas cooperativas (25\%) apontam o marketing como prioridade. As outras duas opções apresentadas no questionário - formação e educação e transparência - em nenhum momento aparecem como prioridade, variando da segunda à quarta posição na lista de objetivos a serem alcançados por meio dos veículos de comunicação adotados pelas cooperativas.

Tendo a informação como prioridade, o profissional responsável pela Assessoria de Imprensa deve ter domínio sobre o Jornalismo Empresarial, considerando algumas variáveis importantes para ser eficiente.

Outra situação fundamental a ser considerada pelos responsáveis pela comunicação dentro das cooperativas são os princípios que regem este modelo socioeconômico. Contudo, quais os princípios que a comunicação pode ajudar a consolidar? Esta foi a questão levantada no início deste artigo e, para tentar solucioná-lo, este tema também foi abordado entre as cooperativas de eletrificação rural pesquisadas. Segundo as cooperativas analisadas, a Assessoria de Comunicação Social, através de seus diferentes profissionais, é fundamental para o cumprimento dos seguintes princípios, nas seguintes proporções:

$1^{\circ}$ ) Adesão voluntária e livre - 50,0\%;

$\left.2^{\circ}\right)$ Gestão democrática pelos membros $62,5 \%$; 
$3^{\circ}$ ) Participação econômica dos membros $75,0 \%$;

$4^{\circ}$ ) Autonomia e independência - 62,5\%;

$5^{\circ}$ ) Educação, formação e informação $75,0 \%$;

$6^{\circ}$ ) Intercooperação - 87,5\%;

$7^{\circ}$ ) Compromisso com a comunidade - 75\%,0.

Analisando o questionário enviado às cooperativas filiadas à Fecoergs, percebe-se que todos os princípios foram apontados como possíveis de serem ajudados a cumprir pelo trabalho do setor de comunicação, sobressaindo-se o $6^{\circ}$, a intercooperação, que superou inclusive o $5^{\circ}$, que se refere exclusivamente à educação, formação e informação. No mesmo patamar está o $7^{\circ}$ princípio - compromisso com a comunidade. Contudo, às explicações de como isso é possível são extremamente genéricas. Analisando algumas das justificativas apresentadas, percebe-se que a comunicação tem realmente o papel de apresentar a cooperativa para o público, que inclui, como já dito, associados, colaboradores e sociedade em geral. Segundo o assessor de comunicação, educação e marketing da Cooperativa 2, todas as cooperativas devem ter um departamento de comunicação, pois este "além de mostrar as ações da cooperativa aos associados e comunidade em geral, também dá transparência as ações, mostrando o compromisso da cooperativa com a comunidade" possibilitando também que muitas iniciativas sejam realizadas em parceria com outras cooperativas. Ainda conforme ele, o setor de comunicação faz um elo entre a cooperativa, seu quadro social e a comunidade em geral devendo "estar sempre ligado na cooperativa, entendendo o trabalho da direção, com ações sociais e de sustentabilidade e levando sugestões para o desenvolvimento da comunidade". É a mesma posição do gerente de comunicação da Cooperativa 6, que acredita que a comunicação serve para fortalecer a relação associado/ cooperativa, coordenando projetos sociais e encaminhando informações de interesse dos públicos externos e internos, por meio de veículos próprios ou terceirizados.

\subsection{Estudo de caso 2: a Ceriluz}

A grande maioria das cooperativas considera os setores de comunicação social fundamentais para a consolidação de todos os princípios cooperativistas, alguns em maior, outros em menor escala, como visto na análise anterior. As respostas, inclusive, superam as expectativas em alguns princípios, onde o vínculo da comunicação não fica explícito.

Para entender melhor esta questão será estudado agora o setor de comunicação da cooperativa Ceriluz. A sua equipe de Assessoria de Comunicação Social está composta por dois profissionais: um jornalista e uma relações públicas, que trabalham de 
forma integrada. Esta composição deixa claro que a sua comunicação está focada principalmente na informação institucional e no relacionamento com seu público interno e externo e menos na publicidade e propaganda, uma vez que não possui um profissional específico desta área. Contudo, isso não significa que não realize campanhas publicitárias de consolidação da marca, ao contrário, uma vez que para este tipo de ação a equipe mune-se do apoio de agências terceirizadas. Um exemplo foi a campanha institucional Ceriluz 45 Anos, iniciada em julho de 2011 e que contou com inserções de anúncios nos jornais da região, spots e jingles nas emissoras de rádio e, inclusive, VTs de 30 segundos em uma emissora de televisão local.

Em termos de relacionamento com seu público a equipe coordena e dá o suporte para eventos direcionados aos associados e colaboradores, através de ações como protocolos, cronograma de atividades, etc, principalmente por sua profissional de relações públicas, com apoio na divulgação prévia e posterior pelo assessor de imprensa. Ainda considerando o aniversário de 45 anos da cooperativa como exemplo, é possível citar o lançamento da Galeria dos Presidentes, no dia 18 de agosto de 2011, contando com a presença de associados, diretores e exdiretores ou seus representantes, ajudando a consolidar assim a história da cooperativa. O setor de comunicação coordenou desde a organização do espaço e do layout da galeria, a divulgação e também o cronograma de apresentação, que contou com protocolo, homenagens e explanações.

No que tange a divulgação de informações institucionais para seu público, por meio de veículos de comunicação, o trabalho é coordenado pelo assessor de imprensa, jornalista graduado. Este coordena envio de notícias para espaços em veículos de comunicação. Atualmente a comunicação com o associado é feita por dois veículos de comunicação próprios: o programa de rádio Informativo Ceriluz, de 15 minutos, que vai ao ar nos sábados e domingos em seis emissoras de rádio em diferentes municípios, em espaços contratados com essa finalidade; e a versão impressa do mesmo informativo, distribuído regularmente entre os associados. Possui ainda o site institucional www.ceriluz.com.br, onde são publicadas as últimas notícias além de informações gerais sobre o trabalho desenvolvido pela cooperativa.

Estes veículos se complementam e levam informações gerais sobre o setor energético, as atividades da cooperativa, o dia a dia do associado, além de notícias de outras áreas como meio ambiente, agricultura, negócios etc. Para o público interno é desenvolvido ainda o Informativo Aqui Entre Nós, com notícias das atividades dos setores e colaboradores, projetos, contratações, 
nascimentos etc. Esta área da comunicação também não ficou de fora das comemorações do aniversário da cooperativa, editando o Informativo Ceriluz Além da Energia Especial 45 Anos, tanto na versão radiofônica quanto na versão impressa, contando a história da cooperativa, de seus diretores e trazendo depoimentos de associados e autoridades da área cooperativista, além de fazer a cobertura dos eventos oficiais que marcaram as comemorações.

\subsection{1 - A ACS e o Cumprimento dos}

\section{Princípios Cooperativistas}

O setor de Assessoria de Comunicação Social da Ceriluz define seu trabalho como um instrumento de divulgação das informações geradas dentro da cooperativa, levando conhecimento e garantindo a transparência aos seus associados, buscando reforçar a sua história e a imagem diante do seu público e da sociedade em geral, isso sempre considerando os princípios que regem o cooperativismo, ajudando a solidificar os conceitos cooperativistas. Ao mesmo tempo que cumpre estes princípios, quer se consolidar dentro da organização como setor essencial diante da direção e de seus associados.

Para ver como isso é possível, foram analisados exemplos práticos retirados dos programas de rádio desenvolvidos pela Assessoria de Comunicação Social da
Ceriluz, neste caso específico, que vão ao ar todos os domingos, às $8 \mathrm{~h} 15$ minutos, na Rádio Progresso, de Ijuí. Será usada esta emissora como referência, contudo, é preciso destacar que o mesmo programa é divulgado todos os sábados, na rádio Repórter, de Ijuí, e nas rádios Jornal da Manhã, Ijuí; Águas Claras, Catuípe; Ciranda, Chiapetta e Querência, de Santo Augusto, sendo estas últimas também no domingo pela manhã, no mesmo horário da Rádio Progresso, em cadeia.

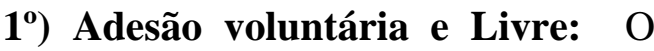

setor de comunicação auxilia no cumprimento deste princípio quando estimula novas adesões de associados, buscando levar até estes os benefícios do cooperativismo. Como caso prático, citamos aqui o programa Informativo Ceriluz do dia 06 de março de 2011, alusivo ao Dia Internacional da Mulher. No programa, os locutores fazem um resumo da participação das mulheres dentro da cooperativa, tanto como associadas, conselheiras ou colaboradoras e, ao final, convidam a todas os ouvintes do programa a aderirem ao cooperativismo se associando à Ceriluz.

\section{$2^{\circ}$ ) Gestão democrática pelos} membros: As cooperativas diferem-se das organizações privadas por terem em seu rol de atividades ações previstas nos princípios que aproximam direção, colaboradores e associados, permitindo que estes últimos 
participem das decisões. Um exemplo são as Assembleias Gerais Ordinárias, que reúnem associados para discutirem o futuro de sua cooperativa. Nas assembleias o processo de comunicação precisa ser efetivo e claro, tendo em vista que se trata do momento maior da democracia dentro de uma cooperativa, quando todos os associados têm a oportunidade de tomar conhecimento da real situação de sua organização, permitindo uma correta tomada de decisões. A Assessoria de Comunicação Social participa de várias maneiras deste processo. Primeiro, pela divulgação da assembleia dos meios de comunicação tornando-a pública. É o que faz a assessoria da Ceriluz no seu informativo de rádio do dia 30 de janeiro, quando apresenta no ar o edital de convocação, deixando clara a possibilidade de participação a todos os associados, inclusive da eleição da nova diretoria da Cooperativa Regional de Energia e Desenvolvimento Ijuí Ltda., ocorrida no dia 04 de fevereiro. No programa foram listados todos os locais onde as urnas estiveram expostas no dia da eleição. Neste caso a comunicação participou também efetivamente desse momento democrático no programa de rádio do dia 06 de fevereiro, quando foi apresentado um resumo da $\mathrm{AGO}$, com o resultado das eleições e com algumas informações contábeis e fiscais da cooperativa, garantindo a transparência da cooperativa, inclusive para aqueles que não puderam comparecer ao evento.

$3^{\text {o) }}$ Participação econômica dos membros: este com certeza é um dos princípios cujo cumprimento tem a menor dependência do setor de comunicação, uma vez que, a participação econômica depende principalmente de decisão da diretoria e dos conselhos de administração e fiscal. Contudo, a comunicação pode ser incluída neste princípio, quando cumpre sua função de divulgar informações que dizem respeito aos resultados econômicos obtidos pela cooperativa, custos e investimentos, que influenciam nas sobras finais a serem divididas. Como exemplo, neste caso, é usado o programa do dia 02 de abril, que tratou da Assembleia Geral Ordinária da Cooperativa de Geração de Energia e Desenvolvimento Social Ltda. - Ceriluz Geração. No programa em questão o locutor faz um resumo dos resultados obtidos pela cooperativa durante o ano de 2010, quando houve um crescimento na geração de energia elétrica que se refletiu no faturamento da organização. Ele também se refere à destinação destes recursos, voltados principalmente a novos investimentos - considerando que a cooperativa está construindo uma nova usina - e em benefícios sociais.

$4^{\circ}$ ) Autonomia e independência: $O$ setor de comunicação auxilia no cumprimento deste princípio, ao divulgar parcerias e 
contratos firmados pela cooperativa, para execução de serviços ou aquisição de produtos e equipamentos. Como exemplo, destacamos aqui o programa de rádio do dia 08 de maio, que tratou de aquisição de veículos e da terceirização do serviço de registro do consumo de energia junto ao associado. A partir destes dados os associados estão cientes dos contratos firmados pelos seus representantes (diretoria) e podem analisar se essas iniciativas não irão comprometer ao $4^{\circ}$ princípio, ou seja, sua autonomia e independência.

\section{$\left.5^{\circ}\right)$ Educação, formação e}

informação: Este é um dos princípios cooperativistas onde mais se aplica o trabalho da Assessoria de Comunicação Social, uma vez que está claro que o associado tem o direito às informações sobre o que acontece dentro de sua cooperativa. O empenho deste setor para cumprir este princípio dentro da Ceriluz fica claro ao se analisar o programa de rádio exibido no dia 12 de junho, na sessão $1^{\mathrm{a}}$. Tendo a cooperativa assinado recentemente contrato que a torna Permissionária de Serviço Público, esta passou a ser regrada pela Agência Nacional de Energia Elétrica (Aneel) que, através da Norma Regulamentadora 414, implantou uma série de direitos e deveres para as cooperativas, atingindo diretamente aos associados. Com objetivo de transmitir todas estas informações ao quadro social, a equipe de comunicação implantou dentro do programa de rádio a série de reportagens "Resolução 414: novas normas para o setor elétrico", que se propôs a resumir os 17 capítulos da normativa em uma linguagem popular. A Assessoria de Comunicação Social, além de dar suporte aos eventos, coordenando a recepção e os protocolos, participa deste processo ao divulgar a ocorrência destes eventos, explicitando datas e locais.

$6^{0}$ ) Intercooperação: $O$ estímulo a este princípio fica claro no Informativo Ceriluz onde são divulgadas as ações do Dia Internacional do Cooperativismo, organizadas pelos setores de comunicação e marketing das cooperativas Ceriluz, Cotrijui, Sicredi e Unimed, de forma conjunta.

$7^{\circ}$ ) Compromisso com a comunidade: Para justificar o papel da comunicação social na consolidação do $7^{\circ}$ princípio destaca-se a programação do dia 16 de julho do Informativo Ceriluz, em sua sessão $1^{\mathrm{a}}$, quando por meio do Projeto Atitude Limpa, divulgou-se informações sobre o trabalho de coleta seletiva de lixo, adotado no município de Ijuí, mas cuja adesão está abaixo do esperado pelo setor público. Aproveitando a presença de técnicos da Secretaria Municipal de Meio Ambiente e de trabalhadores da Associação de Catadores (Acata) que ministraram uma oficina para colaboradores da cooperativa, abriu-se espaço no programa para orientações sobre a correta 
separação de resíduos e seus efeitos. Trata-se de um tema que não é de competência direta da cooperativa, mas, para o qual se abriu espaço pela Assessoria de Comunicação Social, que possui autonomia para definir as pautas a serem utilizadas. Aproveitando-se da expressiva audiência de seu programa de rádio, a cooperativa buscou atingir à comunidade em geral, não só de Ijuí, mas outros 23 municípios, com a expectativa de melhorar a vida dos catadores e o meio ambiente regional.

A comunicação encaixa-se, portanto, perfeitamente dentro do cooperativismo. Por um lado, contribui para o cooperativismo consolidar-se ao ajudar a conquistar credibilidade para a organização que assessora, quando "obter legitimidade aos olhos da sociedade é adotar condutas responsáveis e ferramentas de gestão que auxiliem a transformar o empreendimento em entidade socialmente responsável", conforme Felden (2007), citado por Savoldi (2011).

A comunicação social, especialmente o jornalismo, assim, contribui para o cumprimento do papel social do cooperativismo, uma vez que, no mundo contemporâneo, globalizado e dinâmico, muitas vezes as direções voltam principalmente a sua atenção para as questões econômicas.

\section{CONSIDERAÇÕES FINAIS}

Por meio deste estudo buscou-se avaliar de forma aprofundada e com base em pesquisas exploratórias, até que ponto a comunicação social e as assessorias instaladas dentro das cooperativas conseguem contribuir com o cumprimento dos sete princípios do cooperativismo, resgatando assim parte da preocupação social que pode estar ficando no caminho. O resultado das pesquisas realizadas junto às cooperativas da Fecoergs, especialmente à Ceriluz, de Ijuí, surpreendeu. A conclusão aponta para a contribuição efetiva do setor de comunicação, especialmente da área do jornalismo, no cumprimento de todos os princípios: adesão voluntária e livre; gestão democrática dos membros; participação econômica dos membros; autonomia e independência; educação, formação e informação; intercooperação e compromisso com a comunidade; inclusive sendo encontrados exemplos que comprovem essa afirmação.

\section{A Assessoria de Comunicação Social} precisa pensar muito bem suas estratégias de ação, de modo que realmente consiga obter o resultado que lhe cabe. Com base na pesquisa realizada, percebe-se que as cooperativas da área pesquisada já se esforçam neste sentido, optando por veículos próprios, direcionados exclusivamente ao seu público alvo, destacando-se os informativos impressos e os programas de rádio, sendo este último 
apresentado como o ideal pela maioria das organizações, pelas características do público a quem se destina, expressivamente rural.

Esta relação intensa entre os conceitos de assessoria de comunicação e cooperativismo fica bastante saliente já na sua origem. Ambos surgem no mesmo período histórico, ou seja, no atribulado período da Revolução Industrial e com o propósito semelhante de servir como instrumento de combate as desigualdades sociais e a exploração vigente sobre os trabalhadores da época. O cooperativismo se mostrou uma alternativa de trabalho que permitiu às pessoas desvincularem-se das empresas capitalistas e unirem-se em volta de objetivos comuns, valorizando seu trabalho. A partir do momento que as primeiras cooperativas foram formadas as pessoas deixaram de seguir as regras do capital e passaram a seguir as da cooperação, com a formatação dos princípios do cooperativismo. As assessorias de comunicação surgem também neste contexto de desequilíbrio social. Serviram, principalmente por meio do jornalismo, de instrumento para escancarar a crise vigente,

\section{REFERÊNCIAS}

CIDES, S. J. Marketing para negócios de Sucesso. São Paulo: Universo dos Livros. 2009.

Cooperativismo na Região Noroeste do Rio Grande do Sul: experiências de gestão cooperativa e de promoção do desenvolvimento. Pedro Luis Büttenbender os problemas e carências enfrentados pela população, através de publicações no meio sindical e representativo dos trabalhadores explorados. Mostrando-se eficiente, logo foi utilizado também pelos donos das empresas capitalistas, como forma de mostrar posições em sua defesa e tentar minimizar a imagem negativa que pairava sobre as organizações.

Com base nas informações levantadas neste estudo é possível aduzir que a comunicação é uma ferramenta importante para o cumprimento dos princípios cooperativistas, sendo ainda responsável por garantir a transparência das ações dos diretores das cooperativas, o que é fundamental, uma vez que estes são os representantes legais dos associados que a compõe, devendo prestar conta de seus atos. A Assessoria de Comunicação Social está sim diretamente relacionada às direções e, assim sendo, tem a função de contribuir para o conhecimento do que ocorre dentro das cooperativas junto aos associados, afinal, apesar de não estarem no quadro diretivo, são eles os verdadeiros detentores da cooperativa.

(organizador). Porto Alegre. Sescoop/RS, 2010 .

Gestão da Comunicação: no mundo do trabalho, educação, terceiro setor e cooperativismo / Roseli Fígaro (organizadora). São Paulo: Atlas, 2005. 
FIGUEIREDO, N. T. C. Cooperativas Sociais: alternativa para inserção. Porto Alegre: Evangraf. 2009.

HABERMAS, J. Consciência Moral e o Agir Comunicativo. Rio de Janeiro: Ed. Tempo Brasileiro, 1989.

KOPPLIN, E. Assessoria de Imprensa: teoria e prática / Elisa Kopplin e Luiz Artur Ferraretto. $2^{\mathrm{a}}$ ed. Porto Alegre: Sagra: DC Luzzatto, 1996.

MARCONDES FILHO, C. O espelho e a máscara: o enigma da comunicação no caminho do meio. São Paulo: Discurso Editorial: Ijuí: Editora Unijuí, 2002.

MALHOTRA, N. Pesquisa de Marketing: Uma Orientação Aplicada. $3^{a}$ ed. Porto Alegre: Bookman, 2001.

OCERGS, SESCOOP/RS. Cooperativismo: orientações básicas. Porto Alegre, 2001. OLIVEIRA, D. P. R. Manual de gestão de cooperativas: uma abordagem prática. $2^{\mathrm{a}} \mathrm{ed}$. São Paulo: Atlas, 2003.

PARÉ, A. M. Intercooperação: a formação de redes flexíveis como estratégia competitiva inteligente. Porto Alegre: Sescoop/RS, 2009.

PENA, F. Teoria do Jornalismo. $2^{\mathrm{a}}$ ed. $1^{\mathrm{a}}$ reimpressão. São Paulo: Contexto, 2007.
PACHECO, J. A. Cooperativismo de Trabalho: um estudo na Unitec. In: BÜTTENBENDER, Pedro Luís (Org.). Cooperativismo na Região Nordeste do Rio Grande do Sul: experiências de gestão cooperativa e de promoção do desenvolvimento. Porto Alegre: Sescoop/RS, 2010 .

REGO, F. G. T. Jornalismo empresarial. São Paulo: Summus, 1984.

RICCIARDI, L. Cooperativa, a empresa do século XXI: como os países em desenvolvimento podem chegar a desenvolvidos / Luiz Ricciardi, Roberto Jenkis de Lemos - São Paulo: LTr, 2000.

ROSA, S. G. M. Encantando o Cliente. $4^{\mathrm{a}}$ ed. - Porto Alegre: Sebrae/RS, 2004.

ROSSI, C. O que é jornalismo. São Paulo: Brasiliense, 1981.

SAMPIERI, R. H.; COLLADO, C. F.; LUCIO, P.B. Metodologia de $l a$ investigación. México: McGraw-Hill, 1991.

SAVOLDI, Z. A Responsabilidade Social em Cooperativas Agropecuárias do Rio Grande do Sul. In: BÜTTENBENDER, Pedro Luís (Org.). Cooperativismo na Região Nordeste do Rio Grande do Sul: experiências de gestão cooperativa e de promoção do desenvolvimento. Porto Alegre: Sescoop/RS, 2010 